\title{
The dynamics of the main hydrochemical indicators in small reservoirs of different geographical zones under climate change at the beginning of the XXI century
}

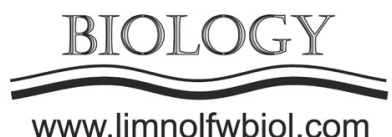

www.limnolfwbiol.com

\author{
Shashulovskaya E.A., Mosiyash S.A.
}

Saratov branch of the All-Russian Scientific Research Institute of Fisheries and Oceanography, Chernyshevsky st., 152, Saratov, 410002, Russia

\begin{abstract}
The dynamics of organic matter and nutrients in small reservoirs of the Ural and Volga rivers basin (Iriklinsky and Sursky reservoirs) in the period of 2016-2019 in the face of climate change is shown. Despite the difference in hydrological, morphometric, geographical characteristics and the level of anthropogenic load, in two reservoirs the values of indicators of allochthonous organic matter $(\mathrm{OM})$, mineral nitrogen and iron depend on the volume of the main water inflow, and the content of easily oxidized and total OM, phosphates and silicon is more determined by the level of bio-production processes.
\end{abstract}

Keywords: climate change, Iriklinsky and Sursky reservoirs, organic matter, nutrients, water regime

At the beginning of the 21st century, climate warming is observed, which is characterized by changes in the thermal regime of rivers and reservoirs, (milder winters with increasing liquid precipitation, a decrease in the ice-free period, an increase in summer temperatures of air and water of water bodies). An increase in river flow during the cold period of the year and a decrease in the flood period was found.

In this paper, we consider the dynamics of the main hydrochemical parameters of two small reservoirs of the Ural and Volga basins in the period of 2016-2019, which is a shallow phase in the long-term fluctuations of the water regime and is characterized by abnormally warm winters for the entire period of instrumental observations.

The Iriklinsky reservoir was created in the former Iriklinsky gorge of the Ural mountain structure and has a complex configuration, representing a chain of lake-shaped extensions (reaches) in the middle and lower part. The reservoir is characterized by weak water exchange, which occurs once every two years. The reservoir volume is $3.26 \mathrm{~km}^{3}$, the average depth is $12.5 \mathrm{~m}$, and the maximum in the dam zone is $36 \mathrm{~m}$. The reservoir was created to guarantee the satisfaction of the water management needs of large enterprises in the Orenburg Region: the Orsk-Khalilovsky Metallurgical and Gaisky Mining and Processing Combines. Wastewater from the Magnitogorsk Iron and Steel Works flows into the upper reaches of the reservoir. High anthropogenic development of the catchment leads to a significant increase in the pollutant content in the abiotic components of the Iriklinsky reservoir (Shashulovskaya et al., 2014).

Sursky (Penza) reservoir was created on the river Sura (Volga basin) in the Penza region $15 \mathrm{~km}$ above the Penza city. The volume of the reservoir is 560 million $\mathrm{m}^{3}$, the water exchange coefficient is about 2.5. The upper reaches of the reservoir are divided into two bays. The river Sura flows into the right bay, into the left bay - river Uza. The average depth of the reservoir is $5 \mathrm{~m}$, the maximum is $15 \mathrm{~m}$. The anthropogenic load on the reservoir is determined, first of all, by agricultural activity.

The influence of climatic changes on the hydrological regime of water bodies manifested itself to a greater extent on the Iriklinsky reservoir, in which, during the period under review, a decrease in the total water inflow $\left(R^{2}=0.98, p=0.01\right)$, an increase in the share of its winter component $\left(\mathrm{R}^{2}=0,80, \mathrm{p}=0.11\right)$ and a decrease in spring $\left(\mathrm{R}^{2}=0.68, \mathrm{p}=0.18\right)$. At the same time, the tendency for a decrease in inflow at the Sura reservoir was weak, and seasonal redistribution was not observed.

In spring, significant amounts of organic matter $(\mathrm{OM})$ of allochthonous origin and mineral nitrogen compounds, between which correlation ratios ( $\mathrm{r}$ $=0.68-0.80$, with $\mathrm{p}<0.05$ ), are delivered to the Iriklinsky reservoir with the main river flood inflow, which accounted for up to $60-70 \%$ during the period under review. In high-water years 2016-2017 seasonal synchronism of fluctuations was observed between the inflow and total (by COD) and easily oxidized OM 
(by $\mathrm{BOD}_{5}$ ). In dry years 2018-2019 a more significant role was played by bioproduction processes. In the study period, taking into account seasonal changes, negative trends were recorded in the influx and the content of allochthonous content (in terms of color and permanganate oxidation (PO)), total and easily oxidized $\mathrm{OM}$ and mineral nitrogen.

In the water of the Sursky reservoir in 2016-2019 a high reliable relationship between the seasonal inflow volume and the color value, concentrations of mineral nitrogen and iron compounds $(\mathrm{r}=0.72-0.83$, $\mathrm{p}<0.05)$ was also noted. It is possible that iron compounds can contribute to an increase in the color of water along with humic substances (Rukovodstvo..., 1977). During the study period, fluctuations in the content of organic matter and nutrients occurred at the same level.

We used the analysis of the main components (PCA) for a better understanding of the ecological state of the studied water systems, characterized by a large set of indicators, and the identification of possible influencing factors on their temporal and spatial variations. The first two components were selected at Iriklinsky reservoir, the first three components - at Sursky reservoir, according to the results of this analysis. The first main factor can be called "catchment", since it is closely related to the total inflow of water into the reservoirs and indicators of color, permanganate oxidizability (PO), and mineral nitrogen. In the Sursky reservoir, this component also includes iron, the increased concentrations of which, as mentioned above, largely determine the color of the water. The second component can be described as "intra-water", since it incorporates indicators that are closely related to bioproduction processes, determining their dynamics in time and space. This is, first of all, easily oxidizable OM associated with phosphates, silicon and iron in the Ural reservoir and with PO and mineral phosphorus in
Sursky.

Thus, the study of the structure of a multidimensional array of hydrochemical indicators by the method of principal components revealed the universality of the processes occurring in the ecosystems of the studied reservoirs, despite the difference in hydrological, morphometric, geographical characteristics and the level of anthropogenic load. The negative trends in the main indicators of the water balance in the Iriklinsky reservoir and the dynamics of hydrochemical indicators associated with them probably reflect the general ecological situation, the leading role in which belongs to changes in climatic conditions. No significant changes in hydrochemical and hydrological characteristics have been recorded in the Sursky reservoir.

According to the trend of the incoming part of the water balance of the studied reservoirs, with a certain degree of probability, it is possible to predict trends in the values of the indicators of allochthonous OM, mineral nitrogen and iron. The content of easily oxidized and total OM, phosphates and silicon is determined by the level of bio-production processes to a greater extent.

\section{References}

Rukovodstvo po khimicheskomu analizu poverkhnostnykh vod sushi [Manual on chemical analysis of land surface waters]. 1977. In: Semenov A.D. (Ed.). Leningrad: Gidrometeoizdat. (in Russian)

Shashulovskaya E.A., Mosiyash S.A., Filimonova I.G. et al. 2014. Compounds of heavy metals in the biohydrocenosis of the Iriklinsky reservoir. In: International. Scientific Conference dedicated to the 100th anniversary of GosNIORH "Fishery ponds of Russia", pp. 1132-1139. http://mail.niorh. ru/download.pub/Conference/Fishery_ponds_2014.pdf (in Russian). 